\title{
Coronary artery disease and the contours of pharmaceuticalization
}

\section{Citation}

Pollock, Anne, and David S. Jones. 2015. "Coronary Artery Disease and the Contours of Pharmaceuticalization." Social Science \& Medicine 131 (April): 221-227. doi:10.1016/ j.socscimed.2014.06.035.

\section{Published Version}

doi:10.1016/j.socscimed.2014.06.035

\section{Permanent link}

http://nrs.harvard.edu/urn-3:HUL.InstRepos:23947103

\section{Terms of Use}

This article was downloaded from Harvard University's DASH repository, and is made available under the terms and conditions applicable to Open Access Policy Articles, as set forth at http:// nrs.harvard.edu/urn-3:HUL.InstRepos:dash.current.terms-of-use\#OAP

\section{Share Your Story}

The Harvard community has made this article openly available.

Please share how this access benefits you. Submit a story.

Accessibility 


\section{Coronary Artery Disease and the Contours of Pharmaceuticalization}

\section{Introduction}

Coronary artery disease (CAD) has dominated mortality for most of the past century, not just in Europe and North America but worldwide. Treatments for CAD, both pharmaceutical and surgical, have become leading sectors of the health care economy. This paper focuses on the therapeutic landscape for CAD in the United States, with particular attention to racialized patterns in the access and utilization of pharmaceutical and surgical interventions. The U.S. context is often critiqued as a site of excessive treatment with both drugs and procedures, and yet there is deep stratification within it - over-treatment in many populations and under-treatment in others. Structural racism produces embodied inequalities in which people of color disproportionately suffer from heart disease, but privileged groups are the recipients of a disproportionate share of the therapeutics. Drugs, therapeutics, and lifestyle change all share a common limitation, in that they focus on individual interventions rather than on the social changes that would have a larger impact on reducing health inequalities. Scholars have written extensively about the pharmaceutical aspects of the individualization of response to disease, but it is important to look at pharmaceuticals as but one part of broader therapeutic responses.

We hope to extend the conversation about pharmaceuticalization explored in this issue by situating pharmaceutical therapies as one element in a broader therapeutic terrain, alongside lifestyle interventions, cardiac surgery, and interventional cardiology. This perspective clarifies the pervasiveness and persuasiveness of pharmaceuticals in an increasingly consumer-driven medicine, as well as the limits of their appeal. Grounded in a critical reading of the medical and social science literature about CAD, this paper describes how CAD came to be seen as a disease that could be managed not just with pills but also with procedures. We provide illustrative examples to explore the pharmaceuticalization and surgicalization of CAD. The paper goes on to discuss the racial stratification of each of these therapeutic modalities. It concludes with discussion of the implications of the morally-laden category of CAD in this context of unequal risk and unequal access. Our central argument is that the expansionary tendencies of pharmaceuticalization can only be understood in light of pharmaceuticals' alternatives, adjuncts, and constraints. 
As coronary artery disease rose to prominence in the United States in the early twentieth century, early medical treatments focused on providing relief during acute attacks, with nitrates to dilate blood vessels and opiates to treat pain. Doctors also encouraged patients to prevent attacks by avoiding physical stress, emotional stress, and other triggers. As epidemiological studies produced increasing evidence about risk factors, especially diet, exercise, and smoking, doctors began to advise patients about lifestyle changes that might slow the course of atherosclerosis. Doctors came to see CAD not as the inevitable consequence of aging, but the contingent pathology of aging in modern society, with its cigarettes, bountiful diet, and sedentary lives. Many believed that, through lifestyle change, patients had the power to prevent the disease altogether. CAD would become important in the emerging understandings of social determinants of health, but doctors and patients also sought to manage the disease through individual lifestyle and clinical interventions. Two strategies of medical intervention emerged in parallel: pharmaceutical and surgical.

\section{CAD as a site of pharmaceuticalization}

As CAD rose to prominence, it became an iconic site for pharmaceutical development and consumption. The history of pharmaceutical treatment for CAD is a paradigmatic example of the history of the blockbuster drug, from thiazides and B-blockers to statins and platelet inhibitors. The succession of blockbusters demonstrates both the complex interplay between disease theory and pharmaceutical practice, and the impact of pharmaceutical marketing, first to physicians and now directly to consumers.

In the framework laid out by Williams, Gabe, and Martin (2011, p. 711), "pharmaceuticalisation denotes the translation or transformation of human conditions, capabilities and capacities into opportunities for pharmaceutical intervention." CAD has been pharmaceuticalized in two ways. One approach addresses risk factors that are imperceptible to patients but assessable by physicians: blood pressure, serum cholesterol, and newer biomarkers such as c-reactive protein. The other manages acute symptoms and risk once CAD has taken root, and includes both the earlier therapeutics that increased blood flow to the heart and eased pain (e.g., nitrates and opiates,) and newer classes of drugs that quiet inflammation or prevent platelet activation and aggregation. 
As one new drug class after another emerged from the 1950s into the 1990s, CAD demonstrated the power of drugs to define diseases and to make them relevant. Narrating the history of the first diuretic for hypertension in the 1950s and 1960s and the first statin for high cholesterol in the 1980s, Jeremy Greene (2007) has shown how the availability of these drugs stabilized the notions of these concepts as disease-like conditions of risk that should be treated. In the decades since, drugs have continued to redefine disease. For example, thresholds for blood pressure and cholesterol levels have been lowered with successive professional guidelines, effectively expanding the ranks of candidates for treatment.

Statins and antihypertensives are key players in the pharmaceutical culture that Joseph Dumit (2012) has called "mass health," in which (1) symptoms are no longer necessary to define disease, (2) clinical trials define risk, and (3) it is normal to be on "drugs for life." As Dumit shows, when patients and physicians recognize a modifiable risk factor, they face a moral obligation to take action to lower that risk. CAD risk factors such as high cholesterol and hypertension are extremely widespread, estimated to affect $26.7 \%$ and $30 \%$ of the U.S. adult population over the age of 20 (National Center for Health Statistics, 2013, p. 205). In America today the most concrete and convenient way to address them is to prescribe pills. Even though much of the distribution of heart disease risk follows social determinants of health rather than individual characteristics or behaviors (Marmot and Wilkinson, 2006; Kreatsoulas and Anand, 2010), the obligation to take action in the face of that risk and suffering falls overwhelmingly on individuals, and adding a pill to a daily regimen is far simpler than transforming long-established habits of diet and physical activity. As anthropologists of pharmaceuticals have noted, "it is easier to satisfy the patients with drugs than with words" (Van der Geest and others, 1996, p. 159). These drugs have been extraordinarily successful, in terms of both profitability and numbers of prescriptions. According to the Centers for Disease Control, high cholesterol drugs were the most commonly prescribed therapeutic class in the U.S. between 2007 and 2010, with $12.5 \%$ of the population receiving at least one prescription in the past thirty days (National Center for Health Statistics, 2013, p. 284).

Even as cardiac pharmaceuticals have been emblematic of the ascendance of this pharmaceutical logic and of the industry's profitability, they are now reaching certain limits. Whereas "medicalization and pharmaceuticalization theorists alike tend towards an overly teleological fixation on the expansion and increase of pharmaceutical prescriptions and uses" 
(Abraham 2010, p. 605), CAD therapeutics may present an instance of pharmaceutical stagnation. Powerful pharmaceuticals already exist that can intervene against each of the key pathophysiological pathways. While additional targets for pharmaceutical intervention have been identified, new products are not imminent. Heart disease is widely considered to be a saturated disease category (Pollock, 2011). Since many of the landmark blockbusters are no longer under patent protection, they face generic competition. Before it went off patent in 2011, the statin Lipitor was by far the top drug in the world in terms of revenue, peaking at $\$ 13.2$ billion in global sales in 2010 (IMS Health, 2012). The newer statin Crestor remains in the top ten drugs in global sales, but the list is now dominated by drugs for asthma, autoimmune disease, mental illness, and cancer. The CAD drug sector faces increasing stagnation.

With the exception of quick-acting nitroglycerin for angina, drugs for CAD have never been the same kind of "quick fixes" as other iconic examples of pharmaceuticalization. Penicillin remains the archetypal "magic bullet": a single dose can cure a patient of syphilis (even though it did not solve the social problem of the disease -- see Brandt, 1987). Benzodiazepines, most famously "mother's little helper" Valium, provided rapid relief for the "psychic tension" of unhappy housewives (Herzberg, 2010). Diuretics, beta-blockers, antihypertensives, and statins, in this context, are far less powerful. They often relieve no symptoms and their impact on the disease cannot be discerned by their consumers. The health effects emerge imperceptibly, over the long term, and only as an amelioration of risk statistics rather than as a guarantee of prevention of adverse events. Impact on individual health is often essentially abstract: for statins in low risk patients -- who form one of the largest markets for the drugs -- it might be necessary to treat 96 patients for five years to prevent a single death (Taylor et al. 2013, p. 11). A pharmaceutical regimen may be quicker to implement than dietary or other lifestyle change, less expensive, and less demanding of patient effort, but the fix can be notably unsatisfying.

Moreover, in prescription guidelines and in direct-to-consumer ads, drugs for CAD are routinely described as supplements to lifestyle change, rather than as alternatives to it. Consumers read these lifestyle messages in diverse ways (Frosch and others, 2011), but the drugs are never completely detached from the moral obligations of diet and physical activity for heart health. This illustrates an important point. Critical scholars of pharmaceuticalization highlight the degree to which pharmaceutical companies seize the terrain of an array of social problems. 
However, they pay less attention to cases in which the pharmaceutical model is compelling but not monopolistic in defining the problem or offering a solution. Just because drug companies try to frame the problem and solution to CAD in particular ways does not mean that those modes will crowd out alternative framings. Education about the need for lifestyle change, and the moral obligations this imposes, have maintained considerable traction as modes of framing CAD. The contours of pharmaceuticalization become clearer when we look at these together. We should see drugs not in isolation, but as part of the terrain of choices for addressing a problem, in this case for CAD. The importance of this perspective becomes even clearer when pharmaceuticals and lifestyle interventions are contextualized with surgical interventions. In this setting, pharmaceuticals sit on a continuum of difficulty and time demands for the individual patient between lifestyle change at one end, which is difficult and never-ending, and surgery at the other end, which has an allure of immediacy and conclusiveness.

\section{Pharmaceuticalization in the context of surgicalization}

As banner blockbuster drugs have pharmaceuticalized CAD, bypass surgery and angioplasty have surgicalized it. Thomas Schlich has used "surgicalization" to describe how certain aspects of surgical thinking, especially ideas about pathological anatomy, became influential in medicine in the nineteenth century (Schlich, 2010, pp. 147-148). We mean something different: a parallel to the concept of pharmaceuticalization, focused on how surgical interventions, like pharmaceutical interventions, come to be seen as the appropriate response to the problem of disease.

While drugs are often exhibited as "quick fixes" in the pharmaceuticalization literature, they are not nearly as quick a fix as surgery. Even at the peak of their blockbuster status, pharmaceuticals never achieved the intuitive appeal and mechanistic allure of surgical interventions such as bypass surgery and coronary angioplasty. Drugs offer a comparatively modest intervention, and they so do invisibly, with efficacy gauged only through physicians' laboratory techniques. Surgery and angioplasty, in contrast, offer a direct, immediate, and mechanistically compelling intervention. They make acute demands on their patients, but with a pay-off: some patients think that the decisive intervention has obviated the need for on-going pharmaceutical regimens. To the extent that there is a cultural sensibility of "no pain, no gain," the surgeon's knife has more promise than an unremarkable tablet. Surgical interventions for 
CAD, however, have not provided the panacea. Doctors have had to reconceptualize postprocedure patients as a group particularly in need of pharmaceuticals. Examining the pharmaceuticalization of CAD in light of its surgicalization offers a window into the tensions and limits of each.

Surgeons had tried since the 1930s to increase blood flow to the heart (Mueller, 1997; Jones, forthcoming). Early efforts were confounded by the difficulty of determining whether the operations had altered the slow, chronic course of CAD. The advent of angiography in the 1950s and 1960s transformed surgeons' vision for coronary revascularization, giving them the ability to diagnose patients more precisely and demonstrate post-operative blood flow (Jones, 2000). Coronary artery bypass grafting, which uses veins and arteries to link the aorta to coronary arteries downstream of major obstructions, quickly became the most popular technique. Cardiologists also developed a competing -- and less invasive -- technique. Coronary angioplasty, first described in 1977, uses a balloon-tipped catheter to stretch open partially obstructed arteries and stents to hold the artery open. Bypass surgery peaked in the United States at 607,000 operations in 1997, but has declined since then. Angioplasty continues to grow, with over 1,000,000 procedures each year through the early 2000s (Jones, 2013, pp. 11-12). Together they form a $\$ 100$ billion industry in the United States.

Bypass surgery and angioplasty can increase blood flow to the heart and produce dramatic and immediate relief of angina. As bypass surgery's proponents described, the "most important factor" in the procedure's success was "achieving an immediate improvement in coronary blood flow" (Austen, 1970, p. 448). It restored a "majority" of patients "a normal life" (Favaloro, 1971, p. 1042). Surgeons and then interventional cardiologists believed that these procedures could prevent heart attacks and prolong survival in patients with stable CAD. The evidence for that claim, however, remains complex and controversial. While revascularization does seem to help patients suffering acute heart attacks, when it is used prophylactically it only provides a survival benefit for the sickest subset of patients (Jones, 2013). So why has prophylactic revascularization been so popular? Money has played a role. Rather than going primarily to pharmaceutical companies, the profits of surgery and angioplasty in the U.S. have gone to surgeons, cardiologists, and their hospitals. However, financial interests of physicians and hospitals alone do not account for the prevalence of revascularization. Psychological factors clearly contribute as well. 
Scholars of pharmaceuticals have studied how marketing and other efforts transform people into patients who see themselves in need of pharmaceuticals (Dumit, 2012). Something similar happens with procedural interventions. Proponents of revascularization actively marketed the direct, mechanical immediacy of bypass surgery and angioplasty. When Cleveland Magazine celebrated the exploits of the local surgeons, it titled its article "Don't Wait Around to Get Zapped by a Heart Attack: Head It Off at the Coronary Artery" (Mearns, 1973). More recently Mt. Sinai Hospital in New York pitched its angioplasty services by appealing to simple intuitive logic. Its full page advertisements in the New York Times Magazine describe how one patient, a plumber, returned to work just two days "after having his own pipes cleaned out" (Mount Sinai, 2011). Patients are told that untreated plaques make them a "walking time bomb" (quoted in Kolata, 2004). Have patients internalized this message? Many certainly have. One survey found that patients undergoing angioplasty expected a ten-year gain in life expectancy as a result of the procedure, an astonishing misunderstanding of what clinical trials have actually shown (Kee and others, 1997).

Physicians also have unrealistic expectations. Curious about why so many cardiologists recommended angioplasty in settings when a survival benefit had not been shown, researchers in San Francisco held focus groups in 2006 with twenty cardiologists (Lin and others, 2007, pp. 106-107). Their informants offered many explanations for the decisions they made. The doctors experienced "anticipatory regret" and worried that they would feel responsible if any of their non-angioplastied patients suffered a heart attack. As one cardiologist explained, "The cath lab staff probably wouldn't let us leave the lab unless we did something with the lesion." The researchers concluded that the "apparent gulf between evidence and practice appears to be motivated primarily by emotional and psychological factors." Opening an artery could be immensely gratifying for cardiologists. As one Boston interventionalist told the New York Times, "This adrenaline rush is why people like me go into cardiology" (quoted in Kolata, 2007). These procedures tap into the long-standing valorization of heroic medicine in the United States (Lerner, 2001). Emboldened by their military experiences during World War II, American surgeons took the risks required to make transplant surgery and cardiac surgery a reality (Fox and Swazey, 1974). This legacy remains alive and well in cardiac surgery and interventional cardiology. One interventional cardiologist described how heroic treatment had become 
"ingrained in the American psyche": patients think that "the worth of medical care is directly related to how aggressive it is" (quoted in Kolata, 2004).

There are problems in seeing surgery as a panacea. Surgery and angioplasty offer an intervention at a single moment in time, but CAD is a chronic process. If risk factors remain unchecked after surgery, atherosclerosis will continue its progressive course, in both the coronary arteries and the bypass grafts. Surgeons recognized this early in the bypass surgery era. Some used the teachable moment of open heart surgery to push the case for lifestyle reform. Surgeons at Stanford in California, for instance, explained in 1972 that "Where atherosclerosis risk factors are present preoperatively, an attempt is made to correct them in the period following by appropriate drug therapy or dietary means." They had some success with this: "Most of these patients can be readily persuaded to modify their eating habits or stop cigarette smoking, having been made aware of the gravity of the situation" (Harrison and Shumway, 1972, p. 57). Bill Clinton's well publicized case provided the most notable example: after his bypass surgery, Clinton transformed his habits, lost weight, and adopted a vegan diet (Martin, 2011). However, commitment to change does not always bring change. As the Stanford surgeons confessed, "preventive efforts are not always successful." A 2011 study found that patients after bypass surgery or angioplasty had significantly lower rates of adherence to statin therapy than patients treated with medication alone (Kulik and others, 2011). A 2013 study found that adherence was lower after bypass surgery than angioplasty (Hlatky and others, 2013). These studies provide little insight into what the patients actually thought. The researchers in 2013 speculated that "patients might feel that a CABG was the definitive treatment of their coronary disease and hence that medications are no longer necessary" (p. 299), but they did not test this. One study that did examine patient attitudes and beliefs about medications after bypass surgery found several factors associated with non-adherence, including concerns about the over-use of medications, as well as older age, higher incomes, and living alone (Khanderia and others, 2008). Other researchers have wondered about the financial costs of adherence (Kulik and others, 2011) and patterns of follow-up care after bypass surgery or angioplasty (Hlatky and others, 2013).

It is essential to understand that physicians do not see treatment as a choice between pharmaceutical and surgical. Instead, they see it as a choice between pharmaceuticals alone or in combination with either bypass surgery or angioplasty. The treatments have complex relationships, sometimes competing, more often enabling. This is especially true with 
angioplasty. In its current state of the art, angioplasty relies on drug eluting stents: special stents coated with polymers that leech medications into the artery wall to prevent restenosis. Patients must also commit to a lifelong regimen of aspirin and other platelet inhibitors to keep the stent from becoming obstructed. Attention to the need for these post-angioplasty medications might explain in part the higher rates of statin adherence seen after angioplasty than bypass surgery (Hlatky and others, p. 300). Angioplasty itself has become pharmaceuticalized.

Patients with CAD must navigate a therapeutic landscape with three intersecting paths: lifestyle change, drugs, and surgery. We might map these out as a slow fix, a quick fix, and a really quick fix, though more work would be needed to see if this taxonomy captures the understandings of patients and providers. There is also another option, often overlooked by analysts but popular among physicians and patients: inaction (no fix). While "sociological debate about pharmaceuticalization and medicalization revolves almost exclusively around psycho-social or 'lifestyle' areas of medicine" (Abraham 2010, p. 605), which some observers consider to be medically inappropriate or unnecessary, CAD remains a leading cause of suffering and the leading cause of death. The stakes are high, and the decisions are far from frivolous. They are, moreover, structured by other constraints. People who experience the serious risks of CAD do so in a racialized terrain of unequal access to care.

\section{Racial stratification and the limits of pharmaceuticals and surgery}

As pharmaceutical and procedural interventions for CAD proliferated, tensions emerged over gender and race, with women and minorities less likely to receive treatment than white men. These disparities highlight the importance of how people come to see themselves -- and to be seen by doctors -- as people in need of treatment, and with which drug and/or surgical procedure. Racial disparities demonstrate this well.

Belief in the existence of relevant biological differences between blacks and whites has deep historical roots (Byrd and Clayton, 2000, Hammonds and Herzig, 2009), and persisted even as medical theory moved towards universal disease concepts and therapies in the late nineteenth century. Theories of black difference have long been especially pronounced with heart disease. In the 1930s, for instance, leading physicians argued that blacks, who had not yet been fully civilized, only rarely suffered from coronary artery disease and similar "diseases of civilization" (Aronowitz, 1998; Pollock, 2012; see also Rosenberg, 1998). 
The study of racial disparities in cardiac care was part of a rising tide of concern about racial disparities in medical treatment in the wake of Civil Rights. When Congress enacted Medicare and Medicaid in 1965, health advocates hoped that the programs would reduce longstanding barriers in access to care for the poor, the elderly, and minorities. Although the government programs did increase health care utilization in these groups, race disparities did not disappear. A 1985 report commissioned by the Department of Health and Human Services, found that minorities "have not benefited fully or equitably from the fruits of science or from those systems responsible for translating and using health sciences technology" (DHHS 1985, p. 1). African American life expectancy lagged behind that of whites; cardiovascular diseases provided nearly one-third of the excess deaths.

Active research through the 1980s and 1990s culminated in the landmark 2003 report from the Institute of Medicine, Unequal Treatment. The report's 764 pages catalogued evidence of disparities in treatment access and outcomes throughout medicine. The fundamental message was clear: "Racial and ethnic minorities tend to receive a lower quality of healthcare than nonminorities" (Smedly, 2003, p. 1). Cardiac care figured prominently throughout the report. Unequal Treatment opened with the story of Robert Tools, an African American man who received an artificial heart (pp. 2-3). This success story highlighted the underlying problem: blacks were less likely to receive bypass surgery or the cardiac medications that might have prevented his need for a transplant. The remainder of the report followed this lead: it devoted more space to cardiovascular care than to any other area of medicine. As the "Executive Summary" explained, racial differences in cardiac care "provide some of the most convincing evidence of healthcare disparities" (p. 5).

\section{Racial Stratification of Pharmaceutical Treatments}

Racial stratification contributes to the contours of pharmaceuticalization in two important ways: in medical theory and practice characterized by racialized associations about drug classes, and in uneven access to pharmaceuticals. In the pharmaceutical blockbuster model (Greene, 2007), each new class of blockbuster supplants previous generations. Yet at the turn of the twenty-first century, there was a striking racialized qualification in this trend: new classes of antihypertensive drugs - especially angiotensin-converting enzyme inhibitors (ACE Inhibitors) were argued to control blood pressure better and to have cardiovascular benefits beyond their 
impact on blood pressure levels, but not in all populations. There were suggestions that ACE inhibitors were less effective in African Americans, who according to this line of argument should instead receive older classes of drugs, especially thiazide-type diuretics (Pollock, 2012). In the landmark ALLHAT trial, which was run by the National Institutes of Health and compared antihypertensive and lipid lowering drugs head-to-head, the older drug class was recommended as first line therapy for everyone, especially blacks (Wright and others, 2005).

The claims of racial difference in drug response have been roundly refuted: there is an overwhelming overlap in drug response across racial groups (Mokwe and others, 2004; Sehgal, 2004). Yet the claim that ACE inhibitors were less effective in African Americans became the conventional wisdom. This in turn became part of the justification of a much more controversial case: the approval of BiDil for heart failure in "self-identified black patients." During the FDA hearings, ACE-inhibitors became the exemplar of differential drug response (Cohn, quoted in Department of Health and Human Services, 2005, pp. 25-27). For Steve Nissen, the chair of the FDA committee that approved BiDil, BiDil's sponsor should get special consideration. As he explained to Robert Temple, from the FDA's Office of Drug Evaluation, "I live in Cleveland, Ohio, Bob. We have a very large African American population. We see a lot of heart failure. As we all know and we are to talk about a little bit later, ACE inhibitors don't work so well in that population. So, when you get information that is potentially very valuable and informative about a group that can be very difficult to treat, you have to give a sponsor some points for going after that" (Nissen, quoted in DHHS, 2005, p. 308). Thus, even though a differential response by race had not been demonstrated convincingly, the patent holders were able to win federal support for a racially-specific indication (Kahn, 2012; Dorr and Jones, 2008). More broadly, race is a major way of sorting medical data, and, relatedly, marketing new products (Epstein, 2007; Whitmarsh and Jones, 2010).

There is another aspect of race and pharmaceuticalization that also matters: uneven access to care. For all of its hype, BiDil was a commercial failure (Huggett, 2008). Even though BiDil was a drug combination based on components available as generics, the pharmaceutical company priced it aggressively. Insurers balked. Moreover, although the company had a plan for distributing it at reduced cost to patients without insurance, it was onerous for patients and their overstretched providers. It is an open question whether BiDil's failure was specific to that drug or to the broader project of racialized drugs. Regardless, it reminds us that the debate about 
race and pharmaceuticals is not only a scientific debate about clinical trial data, but also a market reality for a population that is structurally underserved (Pollock, 2012).

Given that the U.S. population is often considered to suffer from over-treatment, the lesser pharmaceuticalization of African Americans might not be an unequivocal evil. As one study of prescription rates and insurance utilization asked, "was less benefit use among black beneficiaries a result of underprescribing by their physicians or of overprescribing by physicians for treating white beneficiaries?" (Schore and others, 2003, p. 87). Even as the answer to this question remains unclear. the lower prescription and utilization rates of pharmaceuticals among minorities, for CAD and chronic disease more broadly, are a concerning aspect of a context of health disparities (Munshi and others, 2013).

\section{Racial Stratification of Surgical Interventions}

A parallel story played out with the surgicalization of CAD. As doctors and patients decided who would be candidates for bypass surgery and angioplasty, race figured into their assessments. In 1982 cardiovascular epidemiologist Richard Gillum discovered a revascularization gap between blacks and whites. While black patients received a share of all surgery in the United States commensurate with their population, their share of bypass surgery was a fraction of what it should have been (Gillum, 1982, p. 849). Researchers at the University of Alabama confirmed this observation in 1984 when they found that "an inordinately low proportion of blacks undergo coronary arteriography" (Oberman and Cutter, 1984, p. 688). Blacks in Massachusetts received less angiography, angioplasty, and bypass surgery than whites, even when researchers controlled for important clinical, demographic, and socioeconomic characteristics (Wenneker and Epstein, 1989). A Duke study found that the inequalities were most pronounced in the sickest patients, "those predicted to benefit the most from revascularization" (Peterson and others, 1997, p. 480).

Researchers struggled to figure out why cardiac decisions treated black and white patients differently. Some thought that the disparities might be appropriate, an idea that reflected the old consensus that blacks were spared the ravages of CAD. Gillum dismissed this "myth" of black immunity: "United States blacks have one of the highest CHD mortality rates in the world, higher than most white populations in Europe" (Gillum, 1982, p. 849). The utilization disparities could not be explained by differences in relevant clinical characteristics of black and white 
patients (Oberman and Cutter, 1984; Maynard and others, 1986). Insurance status did not explain the gaps either: disparities existed among patients insured by Medicare (Goldberg and others, 1992) and by the Department of Veterans Affairs (Whittle and others, 1993).

One popular theory traced the disparities to differences in patient preferences. One of the first major randomized clinical trials of bypass surgery found that only $80.5 \%$ of black patients accepted referral for surgery, compared with $90.4 \%$ of white patients (Maynard and others, 1986), a finding widely cited as evidence of different preferences (Wenneker and Epstein, 1989; Goldberg and others, 1992). When a New York study reported that black patients were twice as likely to decline surgery as white patients, the researchers concluded that racial differences in bypass surgery rates "are strongly related to a greater reluctance of African-Americans to agree to undergo these procedures" (Sedlis and others, 1997, p. 901). The implication was clear: if a disparity in treatment utilization derived from a disparity in patient preference, then there was no problem. Other researchers remained unconvinced. A phone survey of $2030 \mathrm{CAD}$ patients found no differences in the cardiac health seeking behavior of black and white patients (Crawford and others, 1994). Another study did find a difference in preferences, with black patients less interested in surgery, but much of the difference was explained by their decreased familiarity with the procedure (Whittle and others, 1997). It was a vicious cycle: fewer blacks had had bypass surgery, so fewer blacks were familiar with bypass surgery, so fewer blacks wanted bypass surgery.

Researchers have also grappled with the question of bias. As Gillum noted in 1982, with so few black cardiac surgeons and cardiologists in the U.S., cardiac care for black patients was "largely in the hands of white physicians" (Gillum, 1982, p. 849). This may contribute to the persistent bias in the health care system, though researchers have found bias difficult to prove (Ayanian and others, 1993, p. 2645; Schwartz and others, 1999).

Anxiety generated by evidence of black-white disparities stemmed from the assumption that blacks were being mistreated, that whites had appropriate access to a valuable intervention while blacks missed out. But ever since the emergence of bypass surgery and angioplasty in the 1970s and 1980s, some clinicians and researchers had worried that the procedures were overused. Those suspicions confounded interpretations of disparity data (Wenneker and Epstein, 1989). The Alabama team, for instance, found that black patients had comparable survival rates despite their surgery deficit (Oberman and Cutter, 1984). Only in the subset of patients with the 
most severe forms of CAD did it seem likely that "African-Americans' access to beneficial care was reduced" (Johnson and others, 1993, p. 600). This left researchers grappling with a puzzle. Equity concerns demanded that physicians equalize black and white rates (Ford and Cooper, 1995). But should they raise the black rate or lower the white rate? The answer was often not clear.

\section{Conclusion}

Mortality from CAD in the United States has now fallen 60\% from its zenith in the 1960s (Jones and Greene, 2013). This dramatic decline has coincided with major changes in therapeutic practice, whether pharmaceutical (e.g., antihypertensives, ß-blockers, statins, ACE inhibitors, platelet inhibitors), surgical (e.g., bypass surgery, angioplasty), or institutional (e.g., coronary care units). Physicians have been quick to take credit for the decline, but the historical record is ambiguous. Since the 1970s, epidemiologists and other researchers have struggled to decide which share belongs to medical care and what share belongs to prevention, health education, and broader public health programs. Despite physicians' skepticism about the possibility of lifestyle change, changes in smoking rates, diet, and physical activity (i.e., changes in cardiac risk factors) have likely had the greatest impact on CAD (Capewell and others, 2009; Ford and Capewell, 2011). This debate reveals important tensions about pharmaceuticalization and surgicalization, and medicalization more broadly.

Throughout the twentieth century, patients and doctors sought technical solutions for what they knew to be social problems, even as the problems remain steeped in morality - from penicillin for syphilis (Brandt 1987) to coronary revascularization and pharmaceuticals for heart disease risk reduction. Writing at the peak of the epidemic in the late 1960s, Meyer Friedman emphasized the importance of healthy lifestyles. CAD could be prevented with attention to diet, exercise, smoking cessation, and relaxation: "totally effective prevention can be obtained against coronary artery disease if Western man is prepared or willing to adopt these four habits. Unfortunately he is not. Therefore we are confronted with a constantly increasing incidence of a disease which is almost totally preventable but at a cost few of us are willing to pay" (Friedman 1969, p. 223).

Calls for personal responsibility for health have intensified since then (Brownell and others, 2010). We inhabit an increasingly moralized discourse about lifestyle and personal 
responsibility (Metzl and Kirkland, 2010). "Boring lifestyle change" is routinely trotted out as the "right" way to address high cholesterol, and this carries a moral valence (Weiner, 2010, p. 1544). But patients also seek pharmaceuticals, bypass surgery, and angioplasty. It is easier -and may even cost the patient less -- to take statins or undergo surgery than to change an entrenched habit. At the same time, none of these exist without each other: bypass, statins, and dietary change all inhabit the same therapeutic landscape. If the expansionary tendencies of pharmaceuticals for CAD are isolated from these co-existing alternatives and complements, then understanding of this important site of pharmaceuticalization will be incomplete.

Moreover, attention to racial disparities shows how this trope of pharmaceutical critique, of drugs (and surgery) as an easy way out, slides easily towards troubling victim blaming. It comes from a privileged vantage point in which all options are available to the individual, who should have the moral rectitude to choose correctly. But structural inequalities and the perverse incentives in health care finance both contribute to health disparities and make drugs or surgery easier and cheaper for patients than lifestyle reform. As Williams and colleagues argue, pharmaceuticalization and medicalization, in contrast to value-laden terms such as "disease mongering," "are ideally value-neutral terms with potentially positive and negative faces that remain open to empirical investigation on a case-by-case basis" (Williams and others, 2011, p. 713). The meanings and consequences of pharmaceuticalization depend on its contexts, including questions of over- or under-utilization amid the uneven availability of surgery, pharmaceuticals, and lifestyle change.

Attention to racially stratified CAD can become part of the call by Bell and Figert (2012) to draw together the Western-rooted sociological focus on "pharmaceuticalization" and the global South-rooted anthropological focus on "pharmaceuticalization of public health." Race shapes the distribution of wealth in American society in ways that impact health, especially heart health. Segregated society unevenly distributes safe housing, access to health care, psychosocial stress, nutritious food, and exposure to incarceration and other violence. All of these social inequalities become embodied in diverse ways (Krieger, 1999; Das, 2013), and inform patient perspectives on CAD as part of lived experiences of race and class (Shim 2014). Heart disease is a site at which "the social produces the biological in a system of constant feedback between body and social experience" (Fausto-Sterling, 2008, p. 658; Fausto-Sterling, 2004). Seen in these 
perspectives, CAD outcomes are much more about the broader social world than they are about compliance with technological fixes.

Is pharmaceuticalization a good or bad thing? It depends on what the pharmaceuticals in question offer, and what else is going on around them. For CAD this might include surgery, lifestyle change, and -- far more ambitiously -- restructuring the fabric of society such that CAD and health inequalities diminish. Analysis of the pharmaceuticalization of CAD is enriched by attending to CAD pharmaceuticals' specificity and context, especially their constraints amid uneven access and complementary and competing solutions. 


\section{References}

Abraham, J (2010) "Pharmaceuticalization of Society in Context: Theoretical, Empirical and Health Dimensions," Sociology 44(4): 603-622.

Aronowitz, R (1998) “From the Patient's Angina Pectoris to the Cardiologist's Coronary Heart Disease," in Making Sense of Illness (pp. 84-110). Cambridge: Cambridge University Press.

Austen, WG (1970) “What's New in Cardiac Surgery," Journal of Surgical Research 10: 447-57.

Ayanian, JZ; Udvarhelyi, IS; Gatsonis, CA; Pashos, CL; and Epstein, AM (1993) "Racial Differences in the Use of Revsacularization Procedures After Coronary Angiography," JAMA 269: 2642-6.

Bell, SE, and Figert, AE (2012) "Medicalization and pharmaceuticalization at the intersections: Looking backward, sideways and forward," Social Science \& Medicine 75(5): 775-783.

Brandt, AM (1987) No Magic Bullet: A Social History of Venereal Disease in the United States since 1880. New York: Oxford University Press.

Brownell, KD; Kersh, R; Ludwig, DS; Post, RC; Puhl, RM; Schwartz, MB; and Willett, WC (2010) "Personal Responsibility and Obesity: A Constructive Approach to a Controversial Issue," Health Affairs 29: 379-87.

Byrd, WM, and Clayton, LA (2000) An American Health Dilemma: A Medical History of African Americans and the Problem of Race: Vol. I: Beginnings to 1900. New York: Routledge.

Capewell, S; Hayes, DK; Ford, ES; Critchley, JA; Croft, JB; Greenlund, KJ; and Labarthe, DR (2009) "Life-Years Gained Among US Adults from Modern Treatments and Changes in the Prevalence of 6 Coronary Heart Disease Risk Factors between 1980 and 2000," American Journal of Epidemiology 170(2): 229-36.

Crawford, SL; McGraw, SA; Smith, KW; McKinlay, JB; and Pierson, JE. (1994) “Do Blacks and Whites Differ in Their Use of Health Care for Symptoms of Coronary Heart Disease," American Journal of Public Health 84(6): 957-64.

Das, A (2013) “How does race get 'under the skin'?: Inflammation, weathering, and metabolic problems in late life," Social Science \& Medicine 77: 75-83. 
Department of Health and Human Services, Food and Drug Administration Center for Drug Evaluation and Research (2005) "Cardiovascular and Renal Drugs Advisory Committee, Volume II," Gaithersberg, MD, June 16. Transcript available at http://www.fda.gov/ohrms/dockets/ac/05/transcripts/2005-4145T2.pdf.

Dorr, GM, and Jones, DS (2008) "Facts and Fictions: BiDil and the Resurgence of Racial Medicine," Journal of Law, Medicine \& Ethics 36(3): 443-448.

Dumit, J (2012) Drugs for Life: How Pharmaceutical Companies Define Our Health. Durham: Duke University Press.

Epstein, S (2007) Inclusion: The Politics of Difference in Medical Research. Chicago: University of Chicago Press.

Fausto-Sterling, A (2004) "Refashioning Race: DNA and the Politics of Health Care," differences: A Journal of Feminist Cultural Studies, 15(3): 1-37.

Fausto-Sterling, A (2008) “The Bare Bones of Race," Social Studies of Science 38(5): 657-94.

Favaloro, RG (1971) "Direct Myocardial Revascularization," Surgical Clinics of North America 51(5): 1035-42.

Ford, ES, and Capewell, S (2011) "Proportion of the Decline in Cardiovascular Mortality Disease Due to Prevention Versus Treatment: Public Health Versus Clinical Care," Annual Review of Public Health 32: 5-22.

Ford, ES; and Cooper, RS (1995) "Racial/Ethnic Differences in Health Care Utilization of Cardiovascular Procedures: A Review of the Evidence," Health Services Research 30: 237-52.

Fox, RC; and Swazey, JP (1974/2002) The Courage to Fail: A Social View of Organ Transplants and Dialysis. New Brunswick, NJ: Transaction Publishers.

Friedman, M (1969). Pathogenesis of Coronary Artery Disease. New York: McGraw-Hill Book Company.

Frosch, DL; May, SG; Tietbohl, C; and Pagán, JA (2011) “Living in the 'land of no'? Consumer perceptions of healthy lifestyle portrayals in direct-to-consumer advertisements of prescription drugs," Social Science and Medicine 73(7): 995-1002.

Gillum, RF (1982) "Coronary Heart Disease in Black Populations: I. Mortality and Morbidity," American Heart Journal 104: 839-51. 
Goldberg, KC; Hartz, AJ; Jacobsen, SJ; Krakauer, H; and Rimm, AA (1992) "Racial and Community Factors Influencing Coronary Artery Bypass Graft Surgery Rates for All 1986 Medical Patients," JAMA 267(11): 1473-7.

Greene, J (2007) Prescribing by Numbers: Drugs and the Definition of Disease. Baltimore: Johns Hopkins University Press.

Hammonds, EM; and Herzig, RM (2009) The Nature of Difference: Sciences of Race in the United States from Jefferson to Genomics. Cambridge: MIT Press.

Harrison, DC; and Shumway, N (1972) "Evaluation and Surgery for Impending Myocardial Infarction," Hospital Practice 9: 49-58.

Herzberg, D (2010) Happy Pills in America: From Miltown to Prozac. Baltimore: Johns Hopkins University Press.

Hlatky, MA; Solomon, MD; Shilane, D; Leong, TK; Brindis, R; and Go, AS (2013) "Use of Medications for Secondary Prevention After Coronary Bypass Surgery Compared With Percutaneous Coronary Intervention.” Journal of the American College of Cardiology 61(3): 295-301.

Huggett, B (2008) “BiDil Flops,” Nature Biotechnology 26: 252.

IMS Health MIDAS (2013) “Top 20 Global Products 2012," available at http://www.imshealth.com/deployedfiles/ims/Global/Content/Corporate/Press\%20Room/ Top-Line\%20Market\%20Data\%20\&\%20Trends/Top_20_Global_Products_2012_2.pdf.

Johnson, PA; Lee, TH; Cook, EF; Rouan, GW; and Goldman, L (1993) "Effect of Race on the Presentation and Management of Patients with Acute Chest Pain," Annals of Internal Medicine 118: 593-601.

Jones, DS (2000) "Visions of a Cure: Visualization, Clinical Trials, and Controversies in Cardiac Therapeutics, 1968-1998," Isis 91(3): 504-541.

Jones, DS (2013) Broken Hearts: The Tangled History of Cardiac Care. Baltimore, MD: The Johns Hopkins University Press.

Jones, DS (Forthcoming). On the Origin of Therapies.

Jones, DS; and Greene, JA (2013) "The Decline and Rise of Coronary Heart Disease: Understanding Public Health Catastrophism," American Journal of Public Health 103(7): 1207-18. 
Kahn, J (2012) Race in a Bottle: The Story of BiDil and Racialized Medicine in a Post-Genomic Age. New York: Columbia University Press.

Kee, F; McDonald, P; and Gaffney, B (1997) "Risks and Benefits of Coronary Angioplasty: The Patient's Perspective: A Preliminary Study." Quality in Health Care 6(3): 131-139.

Khanderia, U; Townsend, KA; Erickson, SR; Vlasnik, J; Prager, RL; and Eagle, KA (2013) "Medication Adherence Following Coronary Artery Bypass Graft Surgery: Assessment of Beliefs and Attitudes." Annals of Pharmacotherapy 42(2): 192-199.

Knowles, JH (1977) “The Responsibility of the Individual,” Daedalus 106(1): 57-80.

Kolata, G (2004) "New Heart Studies Question the Value of Opening Arteries," New York Times, 21 March, p. 1.

Kolata, G (2007) "How It Happens: It's Not a 'Plumbing Problem,"” New York Times, 8 April. Kreatsoulas, C; and Anand, SS (2010) "The impact of social determinants on cardiovascular disease." Canadian Journal of Cardiology 26(Suppl C):8C-13C.

Krieger, N (1999) "Embodying Inequality: A Review of the Concepts, Measures, and Methods for Studying Health Consequences of Discrimination," International Journal of Health Services 29(2): 295-352.

Kulik, A; Shrank, WH; Levin, R; and Choudry, NK (2011) "Adherence to Statin Therapy in Elderly Patients after Hospitalization for Coronary Revascularization," American Journal of Cardiology 107: 1409-14.

Lerner, BH (2001) The Breast Cancer Wars: Hope, Fear, and the Pursuit of a Cure in Twentieth-Century America. New York: Oxford University Press.

Marmot, M; and Wilkinson RG, eds. (2006) Social Determinants of Health, 2nd edn. Oxford: Oxford University Press.

Martin, DS (2011) "From Omnivore to Vegan: The Dietary Education of Bill Clinton," CNN, 18 August.

Maynard, C; Fisher, LD; Passamani, ER; and Pullum, T (1986) "Blacks in the Coronary Artery Surgery Study (CASS): Race and Clinical Decision Making," American Journal of Public Health 76: 1446-48.

Mearns, JG (1973) "Effler and Sones and the Boys at Cleveland Clinic Have Taken the You-BetYour-Life Out of Heart Surgery," Cleveland Magazine (November): 2-10. 
Metzl, J; and Kirkland, A (2010) Against Health: How Health Became the New Morality. New York: New York University Press.

Mokwe, E; Ohmit, SE; Nasser, SA; Shafi, T; Saunders, E; Crook, E; Dudley, A; Flack, JM (2004) "Determinants of Blood Pressure Response to Quinapril in Black and White Hypertensive Patients," Hypertension 43: 1202-1207.

Mount Sinai Hospital [Advertisement] (2011) "Ironic that a plumber came to us to help him remove a clog," New York Times Magazine, 17 April, back cover.

Mueller, RL; Rosengart, TK; and Isom, OW (1997) “The History of Surgery for Ischemic Heart Disease," Annals of Thoracic Surgery 63: 869-78.

Munshi, KD; Shih, Y-CT; Brown, LM; Dagogo-Jack, S; Wan, JY; and Wang, J (2013) "Disparity Implications of the Medicare MTM Eligibility Criteria: A Literature Review," Expert Review of Pharmacoeconomics and Outcomes Research 13: 201-16.

National Center for Health Statistics (2013) Health, United States, 2012: With Special Feature on Emergency Care. Hyattsville, MD.

Oberman, A; and Cutter, G (1984) "Issues in the Natural History and Treatment of Coronary Heart Disease in Black Populations: Surgical Treatment," American Heart Journal 108: 688-94.

Peterson, ED; Shaw, LK; DeLong, ER; Pryor, DB; Califf, RM; and Mark, DB (1997) "Racial Variation in the Use of Coronary-Revascularization Procedures," New England Journal of Medicine 336: 480-6.

Pollock, A (2011) "Transforming the Critique of Big Pharma," BioSocieties 6: 106-18.

Pollock, A (2012) Medicating Race: Heart Disease and Durable Preoccupations with Difference. Durham and London: Duke University Press.

Rosenberg, CE (1998) "Pathologies of Progress: The Idea of Civilization as Risk," Bulletin of the History of Medicine 72(4): 714-30.

Schlich, T (2010) The Origins of Organ Transplantation: Surgery and Laboratory Science, 1880-1930. Rochester: University of Rochester Press.

Schore, J; Brown, R; and Lavin, B (2003) Racial disparities in prescription drug use among dually eligible beneficiaries. Health Care Financing Review 25:77-90. 
Schwartz, LM; Woloshin, S; and Welch, HG (1999) "Misunderstandings about the Effects of Race and Sex on Physicians' Referrals for Cardiac Catheterization." New England Journal of Medicine 341(4): 279-283.

Sedlis, SP; Fisher, VJ; Tice, D; Esposito, R; Madmon, L; and Steinberg, EH (1997) "Racial

Differences in Performance of Invasive Cardiac Procedures in a Department of Veterans Affairs Medical Center," Journal of Clinical Epidemiology 50(8): 899-901.

Sehgal, AR (2004) "Overlap Between Whites and Blacks in Response to Antihypertensive Drugs," Hypertension 43(3): 566-72.

Shim, JK (2014) Heart-Sick: The Politics of Risk, Inequality, and Heart Disease. New York: NYU Press.

Taylor, F; Huffman, MD; Macedo AF; Moore, THM; Burke, M; Smith, GD; Ward, K; Ebrahim, S (2013) "Statins for the Primary Prevention of Cardiovascular Disease (review)," Cochrane Database of Systematic Reviews 1:CD004816, pub5.

Van der Geest, S; White, SR; and Hardon, A (1996). "The Anthropology of Pharmaceuticals: A Biographical Approach," Annual Review of Anthropology 25: 153-78.

Weiner, K (2010) "Configuring users of cholesterol lowering foods: A review of biomedical discourse" Social Science \& Medicine 71(9): 1541-7.

Wenneker, MB; and Epstein, AM (1989) "Racial Inequalities in the Use of Procedures for Patients with Ischemic Heart Disease in Massachusetts," JAMA 261: 253-7.

Whitmarsh, I; and Jones, DS (2010) What's the Use of Race: Modern Governance and the Biology of Difference. Cambridge: MIT Press.

Whittle, J; Conigliaro, J; Good, CB; and Joswiak, M (1997) "Do Patient Preferences Contribute to Racial Differences in Cardiovascular Procedure Use," Journal of General Internal Medicine 12: 267-73.

Whittle, J; Conigliaro, J; Good, CB; and Lofgren, RP (1993) "Racial Differences in the Use of Invasive Cardiovascular Procedures in the Department of Veterans Affairs Medical System," New England Journal of Medicine 329: 621-7.

Williams, SJ; Martin, P; and Gabe, J (2011) “The pharmaceuticalisation of society? A framework for analysis," Sociology of Health and Illness 33:710-25.

Wright, JT; Dunn, JK; Cutler, JA; Davis, BR; Cushman, WC; Ford, CE; Haywood, LJ; Leenen, FHH; Margolis, KL; Papademetriou, V; Probstfield, JL; Whelton, PK; and Habib, GB; 
for the ALLHAT Collaborative Research Group (2005) "Outcomes in Hypertensive Black and Nonblack Patients Treated With Chlorthalidone, Amlodipine, and Lisinopril," JAMA 293: 1595-1608. 